\title{
UMA EXPERIÊNCIA DE COLETA SELETIVA EM CONDOMÍNIOS RESIDENCIAIS
}

\author{
*Evelise P. Barboza, *Bruna A. Codima, *Sérgio M. P. Pulice, *Gustavo da C. Talon, \\ *Ana Paula G. Valdiones, **Maria Elena Infante-Malachias
}

\section{RESUMO}

Neste texto, relatamos uma experiência de coleta seletiva de resíduos e Educação Ambiental em condomínios residenciais do bairro Engenheiro Goulart, na zona Leste de São Paulo. Os idealizadores e executores do projeto foram alunos do segundo ano do curso de Gestão Ambiental da Escola de Artes, Ciências e Humanidades da USP (EACH-USP), contemplados com bolsas da Pró-Reitoria de Cultura e Extensão Universitária. O foco principal do projeto foi a abordagem técnica de coleta seletiva dentro de condomínios residenciais, com o objetivo de inserir o trabalho da cooperativa de reciclagem da região dentro da rotina dos condôminos. O grupo trabalhou com a sensibilização e a conscientização dos moradores a respeito da temática ambiental e social. A abordagem de cunho social foi de grande relevância, visto que o grande potencial de renda para a cooperativa era inexplorado devido a dificuldades de acesso. Esta intervenção favoreceu aos condôminos e trabalhadores da cooperativa uma nova maneira de olhar a região na qual habitam.

Palavras-chave: Coleta seletiva. Reciclagem. Condomínios residenciais.

\section{ABSTRACT}

In this work we describe an experience concerned with Trash Selective Collection in residences of Engenheiro Goulart neighborhood. The creators and executors of this project were students of the second year of the course Environment Management at the EACH-USP, fellowships from the Associate Dean's Office of Culture and Extension. The central issue of the project was the technical approach of trash selective collection in residences, with the aim to insert the work developed at the recycling cooperative into the routines of the residents. The group worked with the consciousness of the inhabitants about social and environmental issues. The social approach was very important because a great font of rent was unexplored by the cooperative. This intervention generated a new vision about the region in the inhabitants and the workers of the cooperative.

Key words: Trash selective collection. Recycling. Residences.

\footnotetext{
* Alunos do curso de Gestão Ambiental. ** Docente da Escola de Artes, Ciências e Humanidades da Universidade de São Paulo (EACH-USP). Endereço: Av. Arlindo Bettio, I.00o, Ermelino Matarazzo - São Paulo-SP - 02838-080-e-mail: marilen@usp.br
} 


\section{INTRODUÇÃO}

A ciência moderna tem fragmentado o conhecimento pela grande quantidade de informações disponíveis e pela necessidade de um estudo mais aprofundado. A ideia por trás desta separação do conhecimento seria que a soma de suas partes corresponderia ao todo científico (MORIN, 2000). De fato, essa perspectiva epistemológica produziu, e ainda produz na história da humanidade, muitos e importantes conhecimentos. No entanto, a especialização foi se intensificando, proporcionando um conhecimento cada vez maior em uma amplitude cada vez menor, ignorando o contexto e as relações que existem entre as diferentes áreas (POMBO, 2005).

A partir do século $X X$, reconheceu-se a necessidade de mudanças nas maneiras de conceber e compreender o conhecimento, dependendo cada vez mais de uma integração entre as disciplinas, a partir da constatação da existência de problemas complexos que não poderiam ser abordados apenas por uma única perspectiva. Surgiu, portanto, a necessidade de um método interdisciplinar de produção de conhecimento, resgatando a ideia da ciência adisciplinar (MACIEL \& ALBAGLI, 2005) dos tempos do Renascimento, quando a visão do mundo era estabelecida por um todo, sem divisões.

Segundo Abramovay (2002), não se pretende, com esta visão, abandonar as investigações monodisciplinares, mas sim aproveitar a vantagem de articular abordagens disciplinares e interdisciplinares. Esta afirmação é corroborada por Jacobi, quando afirma que:

É cada vez mais notória a complexidade desse processo de transformação de uma sociedade crescentemente não só ameaçada, mas diretamente afetada por riscos e agravos socioambientais. Num contexto marcado pela degradação permanente do meio ambiente e do ecossistema, a problemática envolve um conjunto de atores do universo educativo em todos os níveis, potencializando o engajamento dos diversos sistemas de conhecimento, a capacitação de profissionais e a comunidade universitária numa perspectiva interdisciplinar. (JACOBI, 2005)

Vivemos tempos de uma emergência mais que ecológica, uma crise de estilos de pensamentos e conflitos epistemológicos que sustentaram a modernidade. Crise pela qual a humanidade transita entre condutas sociais autodestrutivas, degradação da natureza, modelos insustentáveis de consumo e degradação da qualidade ambiental. Neste contexto, o grande desafio da interdisciplinaridade, ainda segundo Jacobi (2005), é enfrentado como um processo de conhecimento que busca estabelecer cortes transversais na compreensão e explicação do contexto de ensino e pesquisa, buscando a interação entre as disciplinas e superando a compartimentalização científica provocada pela excessiva especialização.

Dentro deste panorama, as universidades, enquanto espaços institucionais da educação formal, têm a função de preparar a sociedade para o saber interdisciplinar (POMBO, 2005). A Universidade de São Paulo (USP), com uma evidente visão de futuro, criou, em 2005, uma nova unidade, a Escola de Artes, Giências e Humanidades (EACH), na zona Leste da cidade de São Paulo, que, entre outras importantes missões, tem a de organizar o seu fazer acadêmico sob a perspectiva interdisciplinar.

A EACH vai se constituindo cada vez mais como uma unidade diferenciada e contemporânea, que visa a formação de profissionais diferenciados, aptos para trabalhos em equipe e com uma visão mais complexa da sociedade, da cultura e da ciência, a partir de uma estrutura e de um ambiente acadêmico que promovem o ensino, a pesquisa e a extensão de forma integrada (ARANTES, 2007).

Um dos temas relevantes para a humanidade neste início de milênio, e para ser abordado de forma interdisciplinar, é o meio ambiente. Este pode ser estudado a partir de diferentes áreas da ciência (básicas e da natureza, sociais e humanas, exatas e tecnológicas), e também a partir de diferentes âmbitos organizacionais (público e privado), apontando a necessidade de um conhecimento científico interdisciplinar.

Nesse contexto, um dos dez cursos oferecidos na EAGH, Gestão Ambiental, elaborado a partir dos objetivos que orientam a criação da unidade, possibilita uma visão ampla do funcionamento do ambiente natural com as integrações dos diferentes conhecimentos necessárias para a reflexão ambiental e, consequentemente, as tomadas de decisão na relação sociedadenatureza.

O profissional do curso deve contribuir para o uso sustentável dos recursos naturais e a conscientização 
sobre o consumo e seus impactos, além de ser capaz de diagnosticar e propor soluções na "prevenção, proteção, conservação e o uso sustentável do patrimônio natural (...), considerando os diferentes aspectos envolvidos, entre eles o social, o econômico, o de ordenamento jurídico, o técnico-científico e o biológico", como indicado na página web do curso ${ }^{\mathrm{I}}$.

A interdisciplinaridade proposta também pelas disciplinas que configuram o ciclo básico da EACH, em particular pelo curso de Gestão Ambiental, e a ação social gerada pelas atividades de extensão universitária, favoreceram a elaboração de um projeto sugerido por um grupo de alunos: Coleta Seletiva e Educação Ambiental em condomínios residenciais de Engenheiro Goulart, zona Leste de São Paulo. Os referidos alunos, autores do projeto, cursavam o segundo ano do curso de Gestão Ambiental e foram orientados por um docente do curso de Licenciatura em Giências da Natureza, da EACH.

Tendo em vista a problemática do despejo do lixo e o grande potencial da região de Engenheiro Goulart em relação a cooperativas de catadores de lixo, os integrantes do grupo, cuja formação deu-se por afinidade de ideias, tomaram como principal missão a questão social do entorno, uma vez que se trata de uma região densamente povoada e localizada às margens do rio Tietê.

Apesar da existência de cooperativas na região do bairro escolhido, existem dificuldades para os catadores poderem realizar seu trabalho nos condomínios residenciais existentes. Este fato motivou o grupo a trabalhar na problemática, agindo de acordo com a proposta da Extensão Universitária e da própria USP, de mediar conflitos socioeconômicos através do conhecimento acadêmico. A tríade conscientização, educação e sensibilização ambiental foi o eixo norteador do trabalho. Este teve como foco primário a abordagem técnica de coleta seletiva dentro de condomínios residenciais, com o objetivo de inserir o trabalho da cooperativa associada dentro da rotina dos condôminos. Essa abordagem de cunho social foi de grande relevância, visto que um grande potencial de renda para a cooperativa estava inexplorado devido a certas dificuldades burocráticas.

Para alcançar os objetivos, o grupo tomou como ferramenta principal a abordagem de sensibilização e

I <http://each.uspnet.usp.br/each/cursos.php?pagina=gestaoambiental> conscientização dos moradores para com a temática ambiental na região na qual habitam.

\section{MATERIAL E MÉTODOS}

O presente trabalho foi, em um primeiro momento, uma investigação teórica, tendo como fonte publicações que abordam a parte conceitual do objeto de estudo, visitas para fins exploratórios à prefeitura de Vinhedo, que implantou há nove anos a coleta seletiva no condomínio Vista Alegre, e ao Condomínio Terras de São José II, em Itu. O projeto "USP Recicla" também foi estudado e a responsável pelo programa na EACH, a Profa. Dra. Gisele da Silva Craveiro, auxiliou o grupo no desenvolvimento da atividade de extensão.

Durante o processo houve reuniões periódicas com a orientadora do grupo, Profa. Dra. Maria Elena Infante-Malachias. O grupo contou também com a ajuda do Prof. Dr. Luiz Carlos Beduschi Filho, que ministra a disciplina Educação Ambiental no curso de Gestão Ambiental da EACH.

\section{A. LOCAL E ATORES}

Para a realização do projeto de Cultura e Extensão, foi escolhido o bairro de Ermelino Matarazzo, localizado na zona Leste do município de São Paulo, devido ao próprio papel da EACH para com o desenvolvimento social, ambiental e econômico dessa região.

A Cooperativa Vitória da Penha, localizada na Rua Lagoa de Dentro, I70, Vila Silvia, foi convidada a participar do trabalho e está formalmente vinculada à prefeitura do município. Foram convidados também os condomínios residenciais Parque Ecológico, Vila Flórida e Edifício Jatobá, todos situados próximo à Avenida Dr. Assis Ribeiro. No entanto, o Edifício Jatobá retirou-se posteriormente do projeto, devido a problemas administrativos que, apesar de independentes das atividades realizadas pelo grupo, prejudicavam a sua efetivação.

\section{B. SENSIBILIZAÇÃO E CONSCIENTIZAÇÃO}

Previamente ao trabalho de sensibilização e conscientização dos condôminos, foram realizadas reuniões com os representantes de cada conjunto residencial, onde foi apresentado o projeto aos síndicos 
e discutidos os benefícios potenciais de sua aplicação, bem como as adequações físicas das lixeiras e de rotina que seriam requeridas. Posteriormente, a cooperativa teve contato com os síndicos, que efetivaram a adaptação do local de armazenagem dos resíduos para que não houvesse mistura entre aqueles que seriam destinados à reciclagem dos rejeitos enviados ao aterro. Houve ainda conversas com os funcionários dos edifícios para que fossem informadas as novas rotinas decorrentes da aplicação do projeto.

O trabalho de Educação Ambiental buscou atender as especificidades de cada conjunto residencial, sendo constituído por reuniões com os moradores para informar sobre o início do projeto, distribuição de informativos acerca dos materiais que poderiam ser encaminhados para a cooperativa de reciclagem, visitas "porta a porta" para solucionar dúvidas e avisar das mudanças de rotina do condomínio, fixação de cartazes coloridos e chamativos nos murais para avisar os condôminos sobre a existência da coleta seletiva no local, sobre como colaborar, sobre oficinas de reutilização de materiais na fabricação de brinquedos e sobre debates para que os moradores propusessem formas da coleta seletiva ser mais eficiente em seu condomínio. A periodicidade de tais atividades variava de acordo com a situação presenciada pelo grupo no dia da pesagem dos resíduos domiciliares.

\section{LEVANTAMENTO E ANÁLISE DOS DADOS}

Para analisar o resultado das atividades voltadas para a conscientização dos condôminos, foram previstas pesagens regulares dos rejeitos e do material reciclável. A coleta de lixo realizada pela prefeitura acontecia às terças-feiras, quintas-feiras e sábados, sendo assim, as pesagens eram feitas nesses três dias, na última semana de cada mês, cerca de meia hora antes do caminhão coletor passar no condomínio. Após a pesagem, os valores eram somados e multiplicados por quatro para se obter uma estimativa da produção de rejeitos de cada conjunto residencial. O instrumento utilizado durante as pesagens foi uma balança manual de gancho e os equipamentos de segurança - luvas e máscaras - foram cedidos pela cooperativa.

Os resíduos destinados à reciclagem eram encaminhados à cooperativa e, nas segundas e sextas-feiras da última semana de cada mês, pesados no local em uma balança industrial; depois o material era despejado na esteira e separado (papel, plásticos, vidro, etc.).
Os resíduos orgânicos ou materiais não recicláveis continuavam na esteira e, no final, eram acumulados em um saco de ráfia, que também era pesado e tinha seu valor somado ao peso do lixo destinado a aterros do respectivo condomínio.

Antes de iniciar as atividades de educação ambiental, foi realizada a pesagem de todo o lixo produzido pelos condomínios. Esses dados tornaram-se a referência sob a qual foram elaboradas as metas do projeto. Ou seja, ao término do trabalho, pretendia-se que a quantidade de lixo gerada inicialmente fosse reduzida em $40 \%$, pois esse volume de resíduos passaria a ser separado e destinado à cooperativa de reciclagem.

\section{DIVULGAÇÃO DO PROJETO}

No dia 27 de fevereiro de 2008, o grupo foi convidado a participar de uma reunião realizada na Unidade Básica de Saúde do Jardim Keralux, no bairro de Ermelino Matarazzo, cuja finalidade era discutir a implantação de coleta seletiva nas áreas públicas do bairro, tais como escolas e creches. Em março, o condômino João Denis da Costa convidou o grupo para visitar a instituição em que trabalha e divulgar as atividades realizadas. No dia I4 do mesmo mês, foi realizada uma apresentação na empresa Constarco Engenharia para explicar detalhadamente o objetivo do projeto e o tripé pesquisa, ensino e extensão que constitui a universidade pública.

\section{RESULTADOS E DISCUSSÃO}

O início do projeto foi marcado pelas atividades de divulgação, em edifícios e cooperativas, dos benefícios e implicações do envolvimento no trabalho. A Cooperativa Vitória da Penha logo se mostrou interessada, visto que se pretendia sanar um dos problemas enfrentados pelos cooperados, que era a dificuldade de comunicação com os condomínios do entorno, e participou ativamente de todo o processo, viabilizando e complementando a atuação do grupo. A participação dos conjuntos residenciais foi muito importante, uma vez que não tardaram a aceitar a proposta que, apesar dos pontos positivos, também traria mudanças nas rotinas dos funcionários e condôminos.

No decorrer dos cinco meses de aplicação do projeto, o principal problema, diagnosticado desde o início foi a dificuldade de envolvimento e participação 
dos moradores com o trabalho desenvolvido. No início, tinha-se a intenção de que a panfletagem, enquanto ferramenta de divulgação e comunicação entre o grupo e os condôminos, fosse complementar às demais atividades de conscientização elaboradas. Entretanto, tornou-se um dos principais meios de contato, à medida em que os residentes alegavam não dispor de tempo para participar de oficinas, reuniões, debates, etc. Apesar da pouca eficiência dessa forma de abordagem indireta, notou-se que, quando afixados cartazes coloridos e chamativos nos ambientes comunitários, esses atraíam a atenção do público, levando-os à maior participação.

Em um dos condomínios houve maior liberdade, concedida pelo síndico, para abordagens diretas aos moradores. A intervenção "porta a porta”, a princípio, parecia eficiente, visto que a maioria dos residentes recebeu o grupo e prometeu colaborar com o trabalho. Contudo, as pesagens não refletiam tal comprometimento. Outra observação diz respeito às dúvidas dos condôminos durante a conversa à porta de sua residência, sendo que a questão mais recorrente era se o condomínio iria arrecadar algo com a venda do material reciclado, ou seja, para muitos a questão da coleta e separação dos resíduos domésticos não ia ao encontro das questões sociais presentes em seu bairro. Nesse momento, notou-se que se deveria dar ênfase à sensibilização do público adulto quanto à problemática socioambiental efetivamente.

Já as atividades voltadas ao público infantil conseguiram seu máximo de aproveitamento, embora o número de pessoas participantes fosse menor. As oficinas proporcionaram momentos de reflexão, uma vez que as crianças eram chamadas a debater determinadas situações do cotidiano e também de diversão, pois a cada brinquedo elaborado com materiais reutilizados, havia um tempo para se brincar com ele em grupo. Outro fato que comprovou a efetividade das atividades infantis foi a presença de pais levados por seus filhos na última reunião do grupo com os condôminos.

Um fator que prejudicou o trabalho foi a falta de colaboração e comprometimento por parte da administração do condomínio Vila Flórida com o projeto. Isso fez com que as tomadas de decisões referentes às mudanças físicas e de rotina, bem como em relação às datas de eventos, fossem prejudicadas. Em contrapartida, a administração do Edifício Parque Ecológico demonstrou não só aceitação do projeto como também envolvimento no processo de construção e manutenção da campanha, uma vez que algumas questões práticas relacionadas à coleta foram tratadas diretamente com a cooperativa.

Quanto aos dados obtidos no decorrer do projeto, a partir da quantidade de resíduos e sua destinação, indicaram que, no último mês de trabalho, I3\% dos resíduos coletados foram destinados à reciclagem. Essa informação é relevante, pois a coleta seletiva tinha sido implantada apenas há quatro meses. Esse valor percentual representa algo em torno de $3.300 \mathrm{~kg} / \mathrm{mês}$ de resíduos recicláveis que deixaram de ser enviados a aterros e lixões, para receberem o devido tratamento.

Cabe ressaltar que nem todo resíduo enviado à cooperativa podia ser reciclado: muitos dos materiais coletados deveriam ter sido depositados junto aos rejeitos, cujo recolhimento é feito pelo caminhão coletor da prefeitura. Entretanto, obteve-se também o valor referente ao peso destes, o qual foi utilizado para indicar a eficiência dos métodos de conscientização utilizada pelo grupo junto aos moradores. A partir da quantidade e qualidade dos rejeitos enviados com os materiais recicláveis à cooperativa, era possível notar se a mensagem estava sendo captada pelos condôminos e quais eram os materiais que geravam dúvidas na separação.

No início das atividades do grupo, aproximadamente $28 \%$ dos resíduos destinados à cooperativa não eram efetivamente recicláveis. No decorrer do trabalho, notou-se uma redução desse valor para $23 \%$ como resultado do trabalho realizado com os moradores.

De modo geral, não é possível saber se a quantidade de material reciclável, bem como a qualidade da separação efetuada pelos condôminos, seguem uma tendência positiva do ponto de vista da otimização da separação dos resíduos domiciliares, da geração de renda para os cooperados e da minimização de impactos ambientais, devido ao curto tempo de aplicação do projeto.

É evidente, pelos motivos já descritos, que para cada edifício o grupo obteve diferentes resultados. O condomínio Vila Flórida, anterior ao projeto, não destinava qualquer quantidade de seu rejeito à reciclagem. No último mês de trabalho, aproximadamente IO\% do resíduo gerado pelos seus condôminos tinham como destino a cooperativa Vitória da Penha. Lembrando que desse percentual já foi subtraída a quantia de resíduos enviados indevidamente à cooperativa (30\% de todo material enviado). Já no Edifício Parque Ecológico, que demonstrou maior pró-atividade 
em relação ao projeto, identificou-se que, de todo o resíduo coletado pela cooperativa, $20 \%$ foi destinado indevidamente, tendo um aproveitamento de $80 \%$. Considerando todo o resíduo produzido pelo conjunto residencial, I5\% foram devidamente separados e encaminhados à reciclagem.

\section{CONCLUSÃO}

De acordo com os dados apresentados, não foi alcançada a meta estipulada, ou seja, ao término da intervenção do grupo nos condomínios, não se conseguiu que $40 \%$ dos resíduos domiciliares gerados fossem destinados à separação e reciclagem. Porém, é sabido que este trabalho se baseia em um processo de re-educação dos envolvidos e a variável tempo é extremamente importante na obtenção de resultados. Espera-se, então, que a destinação de materiais para a cooperativa seja cada vez maior, uma vez que o debate iniciado pelo grupo durante a aplicação do projeto aqui descrito - questões socioambientais - vem se ampliando. Por outra parte, verificamos que para esta situação particular, a conscientização dos cidadãos, no caso os condôminos, foi produto da experiência vivida.

Todavia, os resultados obtidos foram satisfatórios, visto que os condomínios não possuíam nenhum tipo de coleta seletiva, e num prazo de apenas quatro meses destinados à educação ambiental, a quantidade de lixo enviada aos aterros pelos edifícios decresceu I5\% no condomínio Parque Ecológico e IO\% no condomínio Vila Flórida.

Quanto à "ponte" estabelecida pelo grupo entre cooperativa e condomínios, acredita-se que os cooperados se beneficiaram do projeto devido à arrecadação dos resíduos dos dois conjuntos residenciais participantes. Portanto, houve um aumento na renda mensal da Cooperativa Vitória da Penha. Contudo, entende-se que a contribuição do trabalho aos cooperados estende-se, principalmente, aos contatos potenciais gerados pela comunicabilidade entre os condomínios do bairro de Engenheiro Goulart-SP. Espera-se que o projeto tenha contribuído para a consolidação de novos programas de coleta seletiva, nos quais haja a parceria entre a cooperativa e edifícios de seu entorno.

Por fim, a contribuição da extensão universitária na formação pessoal e profissional dos integrantes do grupo foi imensa. No início, foi importante a experiência de escrever um projeto, estipular cronograma e orçar as despesas, bem como o aprofundamento dos conhecimentos teóricos acerca do assunto. Durante a efetivação do trabalho, foi significante a alegria pelas lições mais valiosas, relacionadas ao estabelecimento de parcerias com diferentes segmentos e classes sociais, a mediação de conflitos e o convívio proporcionado pelo trabalho em equipe.

Por esta experiência, entendemos que a prática da extensão universitária deveria ser mais estimulada entre discentes e docentes dentro da USP, uma vez que os ganhos são inúmeros, tanto para a formação inicial dos universitários, quanto para a universidade e a comunidade.

\section{REFERÊNCIAS BIBLIOGRÁFICAS}

ABRAMOVAY, R., org. Construindo a Ciência Ambiental. São Paulo, Annablume/ Fapesp, 2002.

ARANTES, V. A., org. Educação e valores: pontos e contrapontos. São Paulo, Summus, 2007.

GURSO DE GESTÃO AMBIENTAL. Escola de Artes Ciências e Humanidades. Disponível em: <http://www.each. usp.br/cursos.php?pagina=gestao-ambiental $>$. Acesso em: mai. 2008.

JACOBI, P. R. Educação Ambiental: o desafio da construção de um pensamento crítico, complexo e reflexivo. São Paulo, 2005. Revista Educação e Pesquisa. v. 3I, n. 2.

MAGIEL, M. L.; ALBAGLI, S. Novos Rumos da Interdisciplinaridade. Liinc em Revista. v. I, n. I, p. I-2, mar. 2005. Disponível em: 〈http://www.ibict.br/liinc〉. Acesso em: jun. 2008.

MORIN, E. Os sete saberes necessários à educação do futuro. São Paulo, Unesco/ Cortez, 2000.

POMBO, O. Interdisciplinaridade e Integração dos Saberes. Liinc em Revista. v. I, n. I, p. 3-15, mar. 2005. Disponível em: 〈http://www.ibict.br/liinc $\rangle$. Acesso em: jun. 2008. 